\title{
Acerca de la traducción de los poemas de Catulo
}

\author{
Lía M. Galán• \\ Centro de Estudios Latinos- \\ Universidad Nacional de La Plata
}

\begin{abstract}
Resumen
Ofrecemos aquí una síntesis del itinerario cumplido en la traducción al español de los poemas de Catulo, las problemáticas presentadas y los principios teóricos que guiaron su ejecución. En primer lugar se considera la traducción del Carmen 64, publicación bilingüe con introducción y notas, un trabajo colectivo, y, en segundo lugar, la traducción de los poemas completos de Catulo, un trabajo individual igualmente publicado con texto bilingüe, introducción y notas. La práctica de la traducción reclama reflexiones teóricas acerca de su naturaleza y función cultural.
\end{abstract}

\section{Palabras clave:}

· Catulo · traducción · latín

\begin{abstract}
We offer here a synthesis of the itinerary completed in the translation into Spanish of the poems of Catullus, the problems presented and the theoretical principles that guided its execution. First we consider the translation of the Carmen 64, bilingual publication with introduction and notes, a collective work, and, secondly, the translation of the complete poems of Catullus, an equally published individual work with bilingual text, introduction and notes. The practice of translation demands theoretical reflections about its nature and cultural function.
\end{abstract}

\section{Key words:}

- Catullus · translation · latin

- Doctora en Letras (Filología Clásica) graduada en la Universidad Nacional de La Plata (1985), donde es Titular del Área de Latín desde 1987. Estudió en la Universidad Complutense de Madrid y en Universidad de Tübingen, Alemania. En 1993 funda el Centro de Estudios Latinos, que dirige desde entonces; en 1996 crea Auster. Revista del Centro de Estudios Latinos. Ha publicado numerosas traducciones y estudios sobre literatura latina y ha dictado cursos y conferencias de su especialidad en Argentina, Brasil, España y Francia. 
La traducción no ha sido un tema de primera importancia en la historia y la teoría de la literatura, como señala Steiner (Steiner, 1980, 306), y ha figurado en ellas de un modo marginal con la única excepción constituida por estudio de la transmisión e interpretación del canon bíblico, si bien se encuentra éste en un terreno especial, donde el problema de la traducción es sólo un aspecto del vasto sistema de la exégesis.

Sólo en las últimas décadas se ha prestado atención a la historia y a la epistemología de la transmisión del sentido, una "hermenéutica diacrónica» en la que la traducción representa un decisivo centro de interés. Steiner afirma:

Abrir las redes de comunicación, propiciar la migración de los parámetros de pensamiento son funciones directas de la traducción. Primero en el interior de una misma lengua y luego de una lengua a otra. No deja de ser extrańo que una función como esta aparezca tan asiduamente como algo anónimo o accidental. (Steiner 1980: 311).

La revalorización de la traducción como elemento constituyente central de la dinámica cultural ha dado lugar a estudios que se multiplican en busca de una sólida teoría de la traducción. Esto evidencia la dificultad de caracterizar un fenómeno multifacético que desborda los límites teóricos. No me detendré en estas cuestiones sino que me referiré a una práctica que reclama, ante los poemas de Catulo, la necesidad inmediata de establecer criterios previos para su ejecución y de enfrentar las posibles dificultades que surjan en el cumplimiento de esta tarea.

Para ingresar en la intimidad particular de cada poema como un objeto único inserto firmemente en una cadena de transmisión textual ha sido necesario despejar algunos conceptos inadecuadamente aplicados, como el de originalidad en poesía, determinado por la noción romántica de la creación poética ex-nihilo, sin un antes definido, que mantuvo por casi dos siglos una especie de ilusión de lo no antes dicho. Esta versión de lo original apenas puede ya hoy sostenerse y esto ha hecho que se pongan bajo nueva consideración los principios de generación, transmisión y traducción de los textos. La concepción ancilar y algo mecánica de la traducción ya no resulta definitiva para abordar un poema, porque sabemos que el trabajo de llevar poesía de una a otra lengua, de adaptar y perfeccionar formas, de imitar imágenes o elaborar léxico, es lo que con mayor derecho puede ser considerado actividad poética.

Una cuestión preliminar, en el caso de textos antiguos, es la selección de las ediciones autorizadas. Previa compulsa, se elige una, en lo posible la más científicamente prestigiosa. En ocasiones, puede que ésta no sea la mejor por cierta limitación que presenta la autoridad de la filología germánica, en sus ediciones admirables por el rigor científico y el monumental acopio de materiales textuales. El problema surge en el momento de relacionar e interpretar estos materiales a los efectos de la fijación del texto. Se manifiestan entonces prejuicios culturales y epocales que conducen a afirmaciones erróneas. Refiero frecuentemente el caso de la afirmación de Wilamowitz (1898), que consideraba que el Carmen 64 de Catulo era la traducción de un original griego perdido y por mucho tiempo se aceptó este sorprendente juicio respaldado por la autoridad científica del filólogo alemán. Unas décadas después, Wilamowitz (1924) se rectificó en parte admitiendo que el poema podía tener su cuota de originalidad. Actuaron allí los prejuicios que han 
perturbado, durante mucho tiempo, el estudio de la literatura latina: los escritores romanos, especialmente los poetas, se limitan a imitar a los escritores griegos, con apenas semejante o menor fortuna. Como si escribir en griego en el siglo VI a.C. fuera más o menos lo mismo que escribir en latín en el siglo I a.C. No nos extenderemos en este problema; remitimos a los excelentes estudios de Galinsky (1992).

A continuación vienen los inevitables comentarios que hay que tratar con cautela ya que es posible acabar sumergido en interminables discusiones filológicas sin solución a la vista. Este es un punto importante cuando se trabaja con traducción y comentario. Necesarios para el especialista que prepara un trabajo científico, para una publicación dirigida al gran público conviene prestarles poca atención, excepto que se trate de un caso fundamental para la interpretación del poema. Revisadas estas cuestiones, comienza lo que es un auténtico trabajo creativo: la traducción.

La edición bilingüe del Carmen 64 fue el resultado de un seminario sobre el poema que desbordó ampliamente el cronograma académico y que, gracias al entusiasmo de los participantes en lograr una traducción publicable, acabó por durar casi dos ańos. Concluido el trabajo, incluí unas palabras preliminares acerca de la empresa realizada. Estos conceptos sobre la traducción ya han sido enunciados (Galán, 2003: 7-10), si bien a propósito de un solo poema, considero apropiado resumir a continuación.

Uno de los aspectos más interesantes de la literatura del pasado lo constituye su aptitud proteica de actualización, su capacidad de mantener una coherencia semántica y estética más allá de la materia (i.e. el idioma), el tiempo y el espacio. La operación por la que esta capacidad se verifica es la traducción. Así, las producciones literarias del pasado - y en particular las del pasado literario grecolatino como fenómeno central de la sociedad gráfica europea - asisten al presente, con sus particulares condiciones de manifestación que significan, a su vez, una materia, un tiempo y un espacio diferentes del original que se traduce.

La traducción, pues, ha sido el constituyente básico indispensable para el desarrollo de las comunidades y de la cultura, factor decisivo del intercambio intelectual que ha diseñado el perfil de nuestras sociedades. A su vez, la traducción tiene un fundamental sentido comunicativo que, cumplido en plenitud, anonada su propia existencia reemplazándola por un verosímil textual. De este modo, un discurso generado en condiciones determinadas (materia —i.e. idioma—, tiempo y espacio) puede incorporarse a sociedades con distintas condiciones, en las que ese discurso recrea sus propiedades semánticas y estéticas a través de lenguas, tiempos y lugares diferentes. Así, todos hemos leído Shakespeare, Dante, Flaubert, sin la sensación de estar leyendo otra cosa, como de hecho ocurre. Y es que una traducción es buena cuando no se nota, cuando el lector percibe que está leyendo Shakespeare, o Flaubert, y no una traducción de Shakespeare o de Flaubert. De este modo, lo que las sociedades reclaman como testimonio cultural, presupone para su existencia la posibilidad de traducción, la posibilidad de apropiación, comprensión e incorporación de un repositorio de producciones escritas que constituye nuestra cultura.

Sin embargo, por obra de premisas del romanticismo y por los imperativos de la sociedad industrial, los trabajos de traducción han sido menospreciados como tarea servil, mecánica y poco creativa. Incluso hoy, en nuestros estudios universitarios de literatura, existen —en correspondencia con la escasa reflexión teórica al respecto- prejuicios que no han sido examinados acerca de la traducción. Leer obras en traducción —algo completamente legítimo si es que uno no piensa hacer 
un trabajo de investigación sobre lo leído - resulta un defecto a disimular, un peccatum inconfesable que arroja sombras sobre la comprensión misma de las obras. En este caso ocurre algo que, de otras maneras y en otras áreas, suele ocurrir en la cultura: ciertas pautas y premisas de lectura, propias de un sector especializado, se extienden a premisas generales, convirtiéndose así en instrumentos de poder. Quien ha leído Homero en griego, por ejemplo, se considera autorizado para hablar sobre lo que escribió Homero, desestimando los posibles juicios de quien ha leído una traducción. Se establece así una jerarquía de receptores, por la que los lectores del supuesto original reclaman mayor autoridad legitimando su propia interpretación, mientras que la turba multa se alimenta con literatura de segunda mano. Nada garantiza que quien haya leído el original lo haya comprendido, ni que los niveles de conocimiento lingüístico sean los apropiados, ni que leyendo una lengua que no es la suya — especialmente cuando se trata de obras extensas - no cometa errores de lectura. Por lo demás, ya sabemos: no basta simplemente con entender las palabras o la sintaxis.

Estas consideraciones consignadas en la presentación del Carmen 64 reflejan la preocupación central de este esfuerzo. Quienes hemos participado en el volumen, realizamos un trabajo de traducción sabiendo que se trataba de "crear» en castellano el Carmen 64 de Catulo. Cumplida la etapa del estudio filológico, de la primera traducción con la asistencia de los instrumenta científicos, y de un examen de la bibliografía especializada, comenzó la parte quizás más interesante y original del trabajo: lograr el verosímil textual, es decir, cancelar la presencia de la traducción. El tiempo que demandó esta etapa igualó al de la primera. Algunos criterios inicialmente fijados tuvieron que ser sometidos a modificaciones y rectificaciones eventuales. Fue necesario discutir criterios léxicos. Por ejemplo, dado que se trataba de un carmen doctus, i.e. una composición sofisticada de alta erudición, fue necesario decidir qué se hacía con los hapaxlegomenos, esas palabras de única aparición que el poeta inventa cumpliendo con su programa estético. ¿Correspondía simplificar las cosas y buscar una palabra castellana oficial para volver más comprensible su significado? De este modo, ¿̨no se estaría desfigurando el sentido original del término, con su impacto de extrañeza lingüística y sus redes intertextuales de referencia? ¿Era, pues, pertinente «inventar» palabras en castellano para reproducir la forma latina? ¿Cómo lograr que el lector — tanto lego como especializado- soportara el invento y no condenara las insolencias del traductor hacia el poeta latino y hacia el idioma castellano? Esto es un breve ejemplo de las problemáticas que se suscitaron en los ajustes de la traducción.

El trabajo fue largo y en algún momento pareció interminable, pero significó un ejercicio intelectual que desbordó la tarea específicamente filológico-científica hacia el campo de la poiesis y sus principios. Finalmente, interesa destacar que se trató de un trabajo colectivo de traducción. Ejercí mis tareas de dirección en la primera etapa; en la segunda, actué como moderadora en los debates sobre formas expresivas. Los integrantes del proyecto cumplieron primero la rigurosa tarea científica para luego recrear el poema en castellano, una productiva práctica de escritura para quien sienta la vocación de hacer poesía. Se intentó siempre acercar a un lector hispanohablante contemporáneo el poema de Catulo en un aceptable verosímil textual y que también un lector no especializado, un lector que no supiera latín, pudiera encontrar gusto en la lectura del texto castellano, sin lamentar sus personales restricciones lingüísticas para encontrar belleza en el texto. 
Catulo es un poeta difícil, en particular en sus poemas extensos. La dificultad se encuentra en la base misma de su poética, que en ocasiones nos recuerda, mutatis mutandis, los postulados gongorinos. Nuestro intento de acercamiento al lector contemporáneo no podría significar la derogación de las condiciones estéticas del texto original, porque entonces habría deficiencia en el verosímil textual. En ocasiones, Catulo es deliberadamente arcaico, o ejecuta complicados desplazamientos semánticos, o experimenta con formas léxicas poco usuales. Su poesía significó un desafío estético en su tiempo. Nada de esto merece ser cancelado.

Si la traducción del Carmen 64 fue una empresa colectiva, la traducción de la poesía completa de Catulo fue una obra individual y solitaria. No privilegiaría la una sobre la otra. En ambas se establecen previamente las características de la traducción y los criterios a adoptar. Por ejemplo, dado que eran ediciones bilingües de páginas enfrentadas, se intentó un correlato de verso latino a verso castellano buscando una coincidencia en la medida de lo posible. También en ambos casos se estableció hacer una traducción en "prosa poética», concepto un tanto elusivo que intenta decir que lo traducido mantiene al menos parte de su naturaleza de poesía en verso. Esto, en suma, significa que se elegirán palabras castellanas acordes con la dignidad del texto y que se recurrirá, ciertas veces, a construcciones sintácticas no de uso corriente en la actualidad de nuestra lengua.

La colección completa de los poemas de Catulo constituyó una tarea tan interesante como ardua. Había estudiado Catulo por décadas, primero para completar mi tesis de doctorado y luego por la necesidad de cursos, seminarios y publicaciones. Por este motivo tenía traducidos los poemas a modo de borrador y sólo me aplicaba con cuidado a los pasajes que, junto con el texto latino, requerían traducción. Se trataba de traducciones correctas que se ajustaban con precisión al original latino pero carecían de labor limae pues esa traducción era un material secundario frente al texto en latín que se estudiaba.

Muy distinta es la empresa de la publicación. Esto representó reflexiones previas. Muchas personas conocerían a Catulo porque leerían mi traducción. Yo tenía que entregarles al poeta Catulo y los lectores que supieran poco o nada de latín deberían tener la impresión de estar leyendo poesía latina. Se trata de un desafío por la gran variedad de temas y tonos de los poemas catulianos, algunos de ellos muy distantes de la sensibilidad contemporánea y de los presupuestos que pueda tener un lector actual sobre lo que es poesía. Los más sencillos son los poemas cultos, dentro de la gran complejidad de estos poemas. Ciertamente es ineludible alterar el texto perdiendo su inicial impacto. Por ejemplo, el falsi parens Amphitryoniades de C. 68, 112, se tradujo por «el falso hijo de Anfitrión", algo no del todo exacto («hijo de Anfitrión falso padre») donde la fuerza creativa está en las dos palabras latinas que ocupan casi todo el verso.

El auténtico problema surge al momento de traducir los poemas burlescos, humorísticos y deprecatorios, con su recurrencia a términos coloquiales u obscenos. En este caso, puede haber pautas editoriales que es necesario atender y efectivamente me recomendaron que buscara una especie de koiné lingüística, evitando el localismo y las formas particularmente rioplatenses. Esto representó un gran problema. Un simple ejemplo: al llegar a Carmen 5. 3, se requiere traducir omnes unius aestimemus assis. Sabemos que en latín dice "(los rumores) todos estimemos en un as", traducción que se prefiere en la ediciones españolas. De inmediato aparece la nota, en la que se explica que un as era una moneda romana de ínfimo 
valor, expresión que ilustra la exhortación a no atender los rumores de los ancianos. No es grato para el lector de poesía toparse con una nota que interrumpa la lectura para explicar algo incomprensible. ¿Cómo guardar en la memoria o cómo citar unos versos en castellano donde decimos que algo «importa un as»? Esta versión, científicamente impecable, me pareció poéticamente desafortunada. La traducción de Petit, en un esfuerzo de castellanización, complica más las cosas: «no nos importen un as...». Se podía recurrir a una forma más amigable para el lector, traduciendo "nada nos importen todos...", evitando la dificultad de la incomprensión, pero entonces se cancelaba el efecto poético de la expresión coloquial. Buscando otra solución, recurrí a giros equivalentes en nuestro idioma. En castellano, una expresión equivalente recurre a metáforas vegetales: cuando algo no tiene importancia para uno, se emplean expresiones como «me importa un pepino» o «me importa un bledo». En consecuencia, quedó «nos importen un bledo», que no es una traducción literal pero que intenta ser una literaria.

Lo más difícil fue la traducción de palabras y expresiones obscenas. Un ejemplo puede ser la aparición en el Carmen 10. 3 del diminutivo scortillum, del que encontramos distintas traducciones hispánicas: una ramerilla (Pérez Vega), una pellejuela (Dolç), una golfilla (Petit); un lector argentino y también uno americano experimentarían gran extrańeza ante el uso de estos términos, algunos casi desconocidos. De este modo se cancelarían los efectos de una palabra vulgar y soez. Optamos, pues, por el más directo, coloquial y ampliamente comprensible de «una putita», que descarta toda extrańeza.

He intentado mostrar algunas de la problemáticas que se presentan al traducir poetas latinos. No obstante, más allá de toda elaboración textual, es fundamental instalar el texto en su contexto histórico-cultural. Hay, en la literatura latina, un marcado arraigo en la realidad contemporánea y dejar esto de lado significa anular un aspecto no menor de su sentido. Aun cuando se considere que el acceso a las culturas largamente alejadas en el tiempo pueda ser insuficiente o estar sujeto a ópticas parciales, es insoslayable la tarea de ingresar al diálogo del poeta con su tiempo. La obra de Catulo requiere ser también estudiada en el contexto de la crisis del fin de la República.

Las obras permanecen, las traducciones pasan lenta o rápidamente. El texto circula por numerosos traductores multiplicándose y extendiéndose para mantener su presencia. El texto es uno, los traductores pueden ser muchos: esta es la grandeza y la miseria de la traducción. Su existencia es necesaria para que la obra perdure pues un texto sin traducción corre el riesgo de extinguirse, pero no dejará de ser un instrumento provisorio en la medida en que una traducción deberá ser sustituida por otra que se adapte mejor a la actualidad de los lectores. Si se asume este trabajo cultural como desafío creativo, la traducción se revela como valioso instrumento para sustentar la experiencia de la escritura poética. 


\section{Referencias bibliográficas}

Catulo (1981). Poesía de Catulo. Prólogo, texto, traducción y notas de Juan Petit. Edición bilingüe. Segunda edición. Barcelona: Los libros de la Frontera. Primera edición 1974.

(1982). Poesías. Texto revisado y traducido por Miguel Dolç. Reimpresión. Madrid: CSIC. Primera edición 1963.

(2005). Poemas. Edición, traducción y comentario de A. Perez Vega y A. Ramírez de Verger. Huelva: Fundación El Monte.

Galán, Lía et al. (2003). El Carmen 64 de Catulo. Texto bilingüe - Estudio Preliminar - Notas. La Plata: Igitur - Colección de Textos Latinos. Galinsky, K. (1992). Classical and Modern Interactions. Postmodern Architecture, Multiculturalism, Decline, and Other Issues. Austin: UTexas Press. Steiner, G. (1980) Después de Babel. Aspectos del Lenguaje y de la Traducción. México: Fondo de Cultura Económica.

\section{Galán, Lía M.}

